\title{
THE OCCURRENCE OF ACUTE RENAL FAILURE IN PATIENTS WITH NEUROPATHIC BLADDERS
}

\author{
By D. J. Grundy, M.B., F.R.C.S., ${ }^{1}$ D. J. Rainford, M.B., M.R.C.P., ${ }^{2}$ and J. R. Silver, \\ M.B., B.S., F.R.C.P. Ed. \& Lond ${ }^{1}$. \\ ${ }^{1}$ Consultant, National Spinal Injuries Centre, Stoke Mandeville Hospital, Aylesbury, Bucks \\ HP2I 8AL. ${ }^{2}$ Consultant in Renal Medicine, Renal Unit, Princess Mary's Royal Air Force \\ Hospital, Halton, Buckinghamshire.
}

\begin{abstract}
A group of patients with neuropathic bladders, who developed acute renal failure, is described. In each instance, sepsis from the urinary tract, its consequences or its treatment was implicated in the aetiology of the renal failure. Aggressive management of acute renal failure in the patients in our study showed their survival and functional renal recovery to be no worse than for similar patients without paraplegia.

This illustrates that these patients presenting with a rare and serious complication of paraplegia should not be abandoned, since aggressive treatment along conventional lines in consultation with renal physicians and urologists was successful in four out of five of our patients.
\end{abstract}

Key words: Acute renal failure; Neuropathic bladder; Septicaemia.

\section{Introduction}

THE high incidence of chronic renal failure in patients with spinal cord lesions is well recognised. It is usually due to one or more of the following factors: ascending urinary infection, stones, obstruction or dilatation of the urinary tract with stasis, hypertension and amyloidosis.

Acute renal failure is less common, but patients with neuropathic bladders may be particularly susceptible. When it occurs, any treatable obstructive lesion should be relieved. We describe five patients with spinal cord lesions who developed acute renal failure, secondary to septicaemia in at least three instances. Following energetic treatment, four survived.

\section{Case Reports}

Case I. A 64-year-old male developed an acute incomplete tetraplegia in August I966 due to a spinal extradural staphylococcal abscess. Nine months later he developed left loin and chest pain. X-rays of the chest and abdomen were thought to be normal, and a diagnosis of an acute urinary tract infection was made. Continuous bladder drainage was instituted and ampicillin given. By the following day his condition had deteriorated. He was dehydrated, sweating, confused and shocked with a temperature of $40 \cdot 7^{\circ} \mathrm{C}$, a pulse rate of $160 / \mathrm{min}$ and a blood pressure of $90 / 60 \mathrm{mmHg}$. Gram-negative septicaemia was diagnosed, ampicillin discontinued and cephaloridine and streptomycin given. The blood pressure became unrecordable and he was anuric for 12 hours, after which he slowly improved. Blood culture grew Proteus and Klebsiella aerogenes, organisms which were also present in the urine, Gentamicin and crystalline penicillin were substituted and improvement was maintained. An intravenous pyelogram on the 29th day of illness showed a left ureteric stone with hydronephrosis. After removal of the stone, which had been missed on the previous plain X-ray of the abdomen, he made a good recovery. 
Case 2. A 27-year-old Libyan male became tetraplegic following a flexion injury of the cervical spine in November 1977. During the next 4 weeks in Libya and $1 \frac{1}{2}$ years in Italy he developed a urethral fistula, pressure sores over the hips and sacrum and 'renal failure'. When flown to England in April 1979 he had a urethral fistula, a $15 \mathrm{~cm}$ diameter sacral pressure sore and a large abscess in the right anterior thigh. On admission, he appeared septicaemic and dehydrated with a systolic blood pressure of $60 \mathrm{mmHg}$. Blood and wound cultures grew Proteus. He received colistin and developed acute renal failure with a blood urea of $20 \mathrm{~m} . \mathrm{mol} / \mathrm{l}$ and a plasma potassium of $7 \cdot \mathrm{I} \mathrm{m} \cdot \mathrm{mol} / \mathrm{l}$, but responded to conservative measures. However, 4 weeks later he developed a large scrotal abscess and septicaemia. He became hypotensive with a low central venous pressure. Blood and wound cultures again grew Proteus. He became anuric and died.

Case 3. A 3I-year-old Israeli male sustained a gunshot wound of the mid-thoracic spine, with paraplegia, during the 1967 Arab-Israeli war. His rehabilitation included transurethral resection and external urethral sphincterotomy for bilateral hydronephrosis and recurrent urinary infections. In July 1979 allopurinol was given for a raised serum uric acid. Eighteen days later he came to England for the International Paraplegic Games. He felt unwell on arrival and presented two days later with fever, rigors and dehydration. His temperature was $39.4^{\circ} \mathrm{C}$ and he appeared septicaemic. Gentamicin was given, but in spite of a normal blood pressure, his urinary output fell from 500 to $50 \mathrm{ml}$ over the next 2 days. The urine grew Proteus. Acute bilateral suppurative pyelonephritis with oliguric renal failure was diagnosed, and subsequently confirmed by the passage of parts of casts of the renal pelves (Fig. I). Blood culture grew Pseudomonas, for which he was given amikacin. The platelet count was $78 \times 10^{9} / 1$ and fibrinogen degradation products greater than $40 \mu \mathrm{g} / \mathrm{ml}$; consequently he was treated with heparin, 500 units intravenously 6hourly. His acute renal failure was treated by peritoneal dialysis with full recovery.

Case 4. A 48-year-old male, an epileptic on phenytoin, sustained a fracture of $\mathrm{T}_{7,8}$ with paraplegia in February 1980. Rehabilitation was slow, he was often confused and tended to pull on his Foley catheter, traumatising the urethra. Four months later, still with a catheter in situ, he became more confused than usual with a pyrexia of $40 \cdot 5^{\circ} \mathrm{C}$. $\mathrm{He}$ had a right acute orchitis and a clinical picture of septicaemia (subsequent blood culture was sterile). The urine grew Pseudomonas. He was given gentamicin. He was also

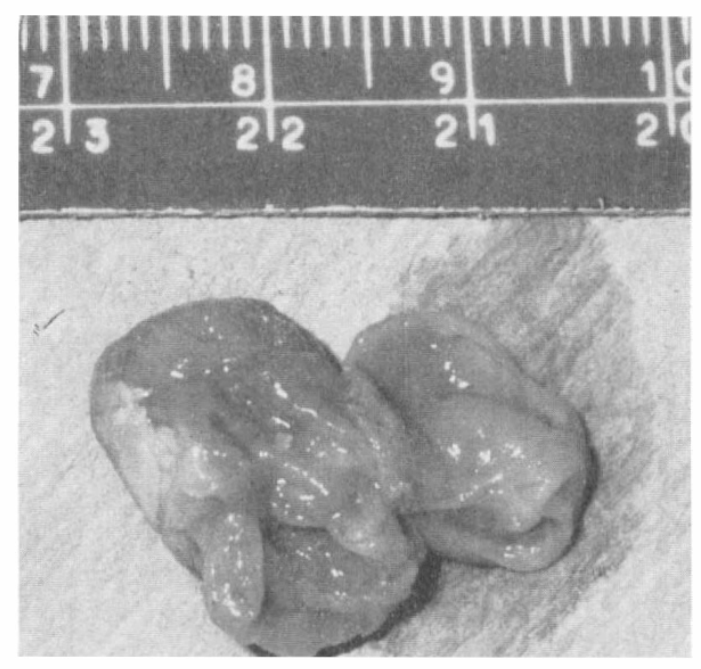

FIG. I

Case 3. Part of cast of the renal pelvis. 
taking phenindione, the prothrombin ratio being $2: \mathrm{I}$. Twenty-four hours later he vomited approximately one litre of blood and the blood pressure was unrecordable for 3 hours. The urinary output dropped to $20 \mathrm{ml} /$ hour. The platelet count was $185 \times 10^{9} / 1$ and fibrinogen titre I in 200 (normal), and although the fibrinogen degradation products were raised ( $40 \mu \mathrm{g} / \mathrm{l})$, this was presumed to be due to the breakdown of blood in the gastrointestinal tract. He was given vitamin $\mathrm{K}_{\mathrm{I}} \mathrm{Io} \mathrm{mg} \mathrm{I} / \mathrm{V}$, cimetidine $200 \mathrm{mg} \mathrm{I} / \mathrm{V}$ 6-hourly, hydrocortisone $200 \mathrm{mg} \mathrm{I} / \mathrm{V}$ 6-hourly, four units of whole blood, two units of fresh frozen plasma and two units of purified protein fraction. The bleeding ceased after 12 hours, the blood urea at this time being $21 \cdot 7 \mathrm{~m} . \mathrm{mol}$ and the plasma creatinine $245 \mu \mathrm{mol} / \mathrm{l}$. The antibiotic was changed to amikacin and he developed a diuresis with recovery of renal function on conservative therapy.

Case 5. A 29-year-old ambulance driver sustained a fracture of T.8,9 with paraplegia in September 1978. He was discharged from hospital in March 1979, well rehabilitated and on condom urinary drainage, but in May 1980 was re-admitted because of early hydronephrosis associated with a large residual urine. External urethral sphincterotomy was performed, following which the intravenous pyelogram returned to normal, with no evidence of stones. He remained well at home until 4 April I98I when he developed fever and vomiting. His urine was cloudy, and co-trimoxazole was prescribed, but he deteriorated and was admitted to his local hospital 6 days later, dehydrated, in acute renal failure. He had a Proteus urinary infection and a blood urea of $30 \mathrm{~m} . \mathrm{mol} / \mathrm{l}$. He was catheterised, responded to peritoneal dialysis and gentamicin and was discharged on 24 April. On the following day, whilst in the diuretic phase of acute renal failure, he
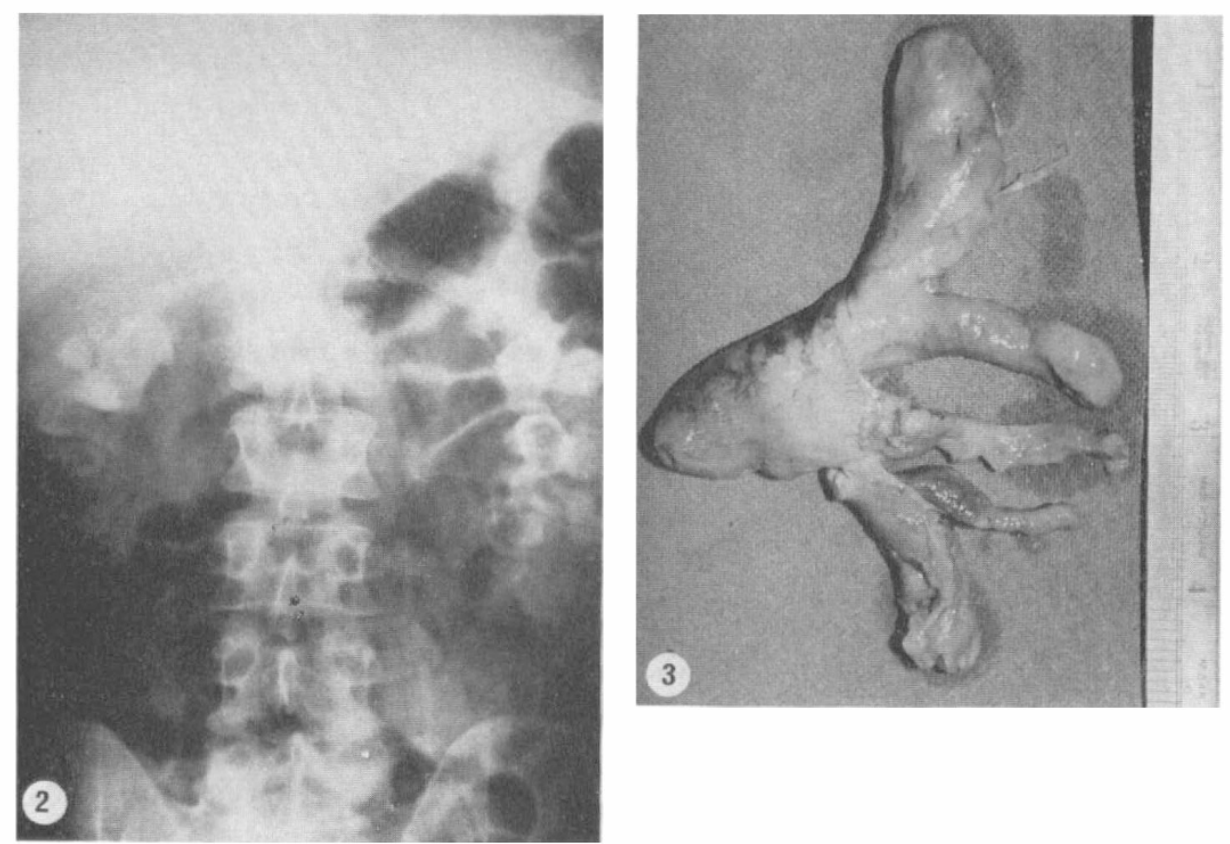

FIG. 2

Case 5. Intravenous pyelogram, 20-minute film, showing bilateral hydronephrosis, with multiple filling defects in the renal pelves and calyces.

FIG. 3

Case 5. Intact staghorn matrix stones removed from left renal pelves-intact stone from left, removed 
developed rigors and a clinical picture of septicaemia, although blood culture was sterile. He was admitted to the National Spinal Injuries Centre, restarted on gentamicin, and an intravenous pyelogram on 28 April showed bilateral hydronephrosis with multiple filling defects in the renal pelves and calyceal systems. A repeat pre-operative intravenous pyelogram on I I May was similar (Fig. 2) but an 8-hour film showed obstruction of the upper urinary tracts, more marked on the left. At left pyelolithotomy on I2 May and right pyelolithotomy on 22 May large staghorn matrix stones were successfully removed from the renal pelves (Fig. 3).

\section{Discussion}

The mortality rate of acute renal failure is high, particularly when associated with septicaemia (Kennedy, Burton, Luke, Briggs, Lindsay, Allison, Edward and Dargie, I973) even without the additional hazards of paraplegia. With their generally high incidence of urinary tract complications, several factors predispose paraplegics to acute renal failure.

\section{Urinary Tract Infection}

All five had infected urinary tracts, and in at least four there was an acute exacerbation: an infected hydronephrosis associated with a ureteric stone in Case I; acute suppurative pyelonephritis, possibly with an element of obstruction caused by the passage of large casts down the ureter in Case 3; acute orchitis in Case 4, and an acute urinary infection associated with bilateral renal matrix stones in Case 5 .

The flare-up, a clinical condition characterised by high fever and rigors, occurs frequently in paraplegics. It is thought to be an acute urinary tract infection, usually associated with a blocked catheter, bladder outlet obstruction or obstruction by a stone. In the vast majority of cases, blood culture is sterile, and it is possible that symptoms are largely due to the release of an endotoxin. However, in a minority of patients septicaemia undoubtedly occurs, and in three of our patients, positive blood cultures of Gram-negative organisms were obtained. It is likely that septicaemia was present in the other patients. The factors predisposing to septicaemia in our patients are shown in Table I. Urinary tract sepsis is still the commonest cause of death in paraplegia (Tribe 1963; Tribe and Silver, 1969), and the incidence of septicaemia is generally underestimated (Silver, Martindale and Moulton, 1970). It is indeed surprising that it is not more commonly seen. Normally there is a balance between the multiplication of organisms and their removal by the defence mechanisms of the body. When there is impaired drainage of infected urine, or when the defence mechanisms of the body are overwhelmed by widespread sepsis, then septicaemia, often resulting in hypotension with poor renal perfusion, is likely to occur. We believe that in at least three of our patients, acute renal failure was due to Gram-negative septicaemic shock.

\section{Obstruction}

In Case I, the infected hydronephrosis was due to ureteric obstruction by a stone; in Case 3 it is possible that an element of obstruction was caused by the passage of parts of casts of the renal pelves; and in Case 5, similar material forming bilateral matrix stones filling the renal pelves and calyces was present. Thus in two of our patients, obstruction in the urinary tract was a major cause of acute renal failure, and was possibly contributory in Case 3. The differential diagnosis of radiolucent filling defects in the upper urinary tract must include low-density 


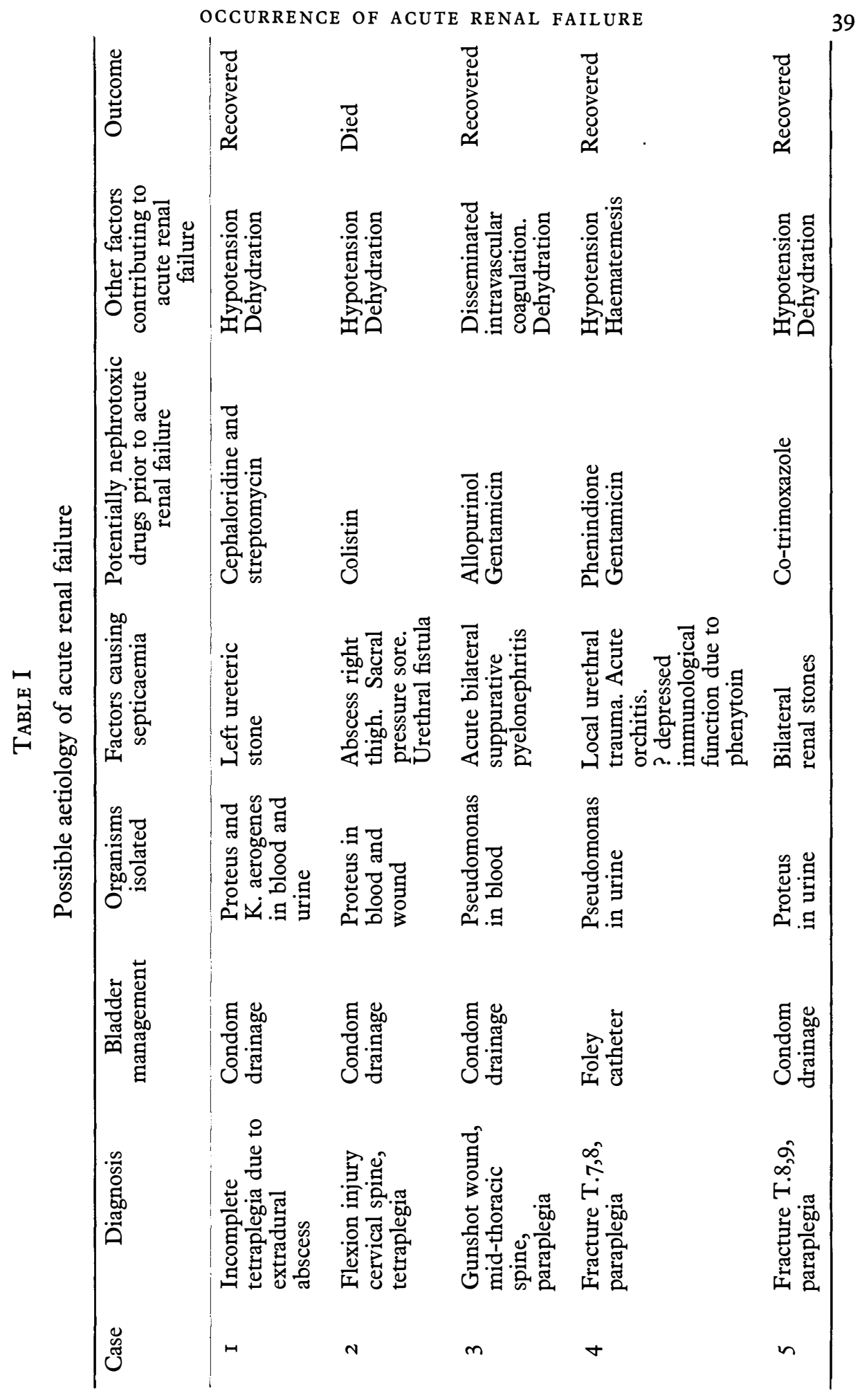


stones, blood clot and tumour. In Case 5 the clinical presentation made a diagnosis of low-density stones most likely.

Whilst renal stones are usually thought to be a late complication of paraplegia we have seen one occurring as soon as Io weeks after injury. Nuseibeh and Burr (I98I) surveyed I025 deceased patients who were first admitted to the National Spinal Injuries Centre between I944 and 1969, and concluded that of patients developing upper urinary tract stones, I 5 per cent do so within 12 months of the spinal cord lesion. Surgically treatable obstruction should, therefore, always be considered as a possible cause of acute renal failure in paraplegics, even in the first few months after injury.

\section{Hypotension/Salt and Water Depletion}

Four of our patients were hypotensive for significant periods, and the resulting poor renal perfusion could have been a factor in the onset of acute renal failure. The latter is more likely to occur in patients who are salt and water depleted. Patients who have obstructive uropathy are often salt losers, and this will increase their predisposition to acute renal failure from nephrotoxic or vasomotor insult. Because of the lability of the circulation in the paraplegic, the state of hydration is more difficult to evaluate and central venous pressure monitoring is recommended in the severely ill patient.

\section{Disseminated Intravascular Coagulation (DIC)}

The role of DIC and its relationship to endotoxinaemia in the pathogenesis of acute renal failure has been well reviewed by Wardle (1975). DIC is described as a common feature in patients with shock (Lasch, I969), and is also commonly seen in septicaemic states (Corrigan, Ray and May, 1968). Frank DIC was present in Case 3 and may have been contributory to the development of renal failure.

\section{Drugs}

Potentially nephrotoxic drugs constitute an added hazard in the treatment of the severely ill paraplegic. In Case $\mathrm{I}$, anuria occurred $\mathrm{I} 2$ hours after administration of cephaloridine and streptomycin, but the synergistic nephrotoxic action of these two drugs had not yet been reported (Kanfer, Kourilsky, De Signeux and Mayaud, 1974) when used in this instance. The exact time relationship of the administration of colistin to the onset of renal failure was not well documented in Case 2, as the patient was not under our care at the time, but there is no doubt that colistin carries a high risk of nephrotoxicity (Koch-Weser, Sidel, Federman, Kanarek, Finer and Eaton, 1970), and it is difficult to justify its continued use as a systemic antibiotic. In Cases 3 and 4 oliguria ensued 24 hours after the administration of gentamicin, a period too short to implicate the drug as a cause of acute renal failure. It is known that phenytoin sometimes depresses immunological function (Sorrell, Forbes, Burness and Rischbieth, I97I), and this could have been a factor in the onset of septicaemia and renal failure in Case 4. Patients 3 and 4 had also taken allopurinol and phenindione respectively for a much longer period, and it is not possible to state the part played by these drugs in the aetiology of the acute renal failure. The use of the potentially nephrotoxic gentamicin (Saltissi, Pusey and Rainford 1979) in Cases 3, 4 and 5 was felt completely justified, as Gram-negative septicaemia, especially in the presence of severe paralysis, carries a high mortality 
rate and demands that the most effective drug be used. It is possible that cotrimoxazole was a factor in the onset of acute renal failure in Case 5. The exact role of the above drugs in the aetiology of the renal failure in our patients remains uncertain.

\section{SUMMARY}

The occurrence of acute renal failure is described in five patients with neuropathic bladders. It is suggested that this group of patients may be particularly susceptible to the condition. Possible causative factors include urinary tract infection, obstruction in the urinary tract, hypotension, salt and water depletion and drugs. Three of the patients had confirmed septicaemia. Aggressive treatment along conventional lines, in consultation with renal physicians and urologists, was successful in four of the five patients.

Acknowledgment: We wish to thank Dr H. B. McMichael, who treated one of the patients.

\section{RÉSUMÉ}

L'occurence de la faillite renale aigue est decrie en cinq malades avec vessies neuropathiques.

Ce groupe de malades est probablement particulièrement susceptible à cette condition.

Les facteurs causatifs comprennment l'infection ou l'obstruction du tract urinaire, l'hypotension, l'épuisement des sels et de l'eau, et les medicaments.

Trois de cinq malades avaient les septicemies confirmées.

Le traitement aggressif selon les lignes conventionelles en consultation avec les specialistes des reinset l'urologist ont obtenu succès en quatre des cinq malades.

\section{ZUSAMMENFASSUNG}

Das Auftreten eines Akuten Nierenversagens wird am Beispiel von fünf Patienten mit Blasenlähmung beschrieben. Es wird angenommen, dasse diese Patientengruppe besonders anfällig hierfür ist. $\mathrm{Zu}$ den verursachenden Faktoren gehören Harnwegsentzündung, Blockierung der harnableitenden Gafässe, Bluntunterdruck, Erschöpfung des Salz- und Wasserhaushalts und Medikamente. Bei drei Patienten wurde eine Blutvergiftung festgestellt. Bei vier von den fünf Patienten war eine energische, konservative Behandlung unter Einbeziehung von Nephrologen und Urologen erfolgreich.

\section{REFERENCES}

CoRrigan, J. J., RAY, W. L. \& MAY, N. (I968). Changes in the blood coagulation system associated with septicaemia. N. Eng. F. Med., 279, 85I-856.

Kanfer, A., Kourilsky, O., De Signeux, R. \& MAYAUd, C. (1974). Anurie après traitement par le cephalotine et la streptomycin avec baisse transitoire du complémént sérique. Presse Med., 3 (38-40), 2508. 9-23.

Kennedy, A. C., Burton, J. A., Luke, R. G., Briggs, J. D., Lindsay, R. M., Allison, M. E. M., EDWARD, N. \& DARGIE, H. J. (1973). Factors affecting the prognosis in acute renal failure. Quarterly f. Med., 42, 73-86.

Koch-WeSER, J., Sidel, V. W., FEDERMAN, E. B., KanAREK, P., Finer, D. C. \& Eaton, A. E. (1970). Adverse effects of sodium colistimethate. Manifestation and specific reaction rates during 317 courses of therapy. Ann. of Int. Med., 72, 857-868.

Lasch, H. G. (1969). Coagulation disturbances in shock. Postgrad. Med. F., 45, 539-542.

NUSEIBEH, I. \& BURR, R. G. Some indices of reduced survival in paraplegia. Presented at I98 I Annual Scientific Meeting, International Medical Society of Paraplegia.

SAltissi, D., Pusey, C. D. \& RAINFord, D. J. (1979). Recurrent acute renal failure due to antibiotic-induced interstitial nephritis. $B r . M e d . \mathcal{F}$., I, I I82-I I83. 
Silver, J. R., Martindale, J. H. \& Moulton, A. (I970). Septicaemia-the forgotten complication of paraplegia. Paraplegia, 8, I28-I42.

Sorrell, R. C., Forbes, I. J., Burness, F. R. \& Rischbieth, R. H. C. (I97I). Depression of immunological function in patients treated with phenytoin sodium (sodium diphenylhydantoin). Lancet, 2, I233-1235.

TribE, C. R. (1963). Causes of death in early and late stages of paraplegia. Paraplegia, $\mathbf{I}$, 19-47.

Tribe, C. R. \& Silver, J. R. (1969). Renal Failure in Paraplegia, 3-I8. Pitman Medical, London.

WARDLE, E. N. (1975). Endotoxinaemia and the pathogenesis of acute renal failure. Quarterly F. Med., 44, 389-398. 